\title{
Effects of different litters on ammonia emissions from chicken manure
}

\author{
Hequn Tan ${ }^{1,2^{*}}$, Meng Li ${ }^{1,2}$, Dengfei J ie ${ }^{3}$, Yafang Zhou ${ }^{1,2}$, Xin'an $\mathrm{Li}^{1,2}$ \\ (1. College of Engineering, Huazhong Agricultural University, Wuhan 430070, China; \\ 2. Key Laboratory of Agricultural Equipment, Ministry of Agriculture and Rural Affairs of China, Wuhan 430070, China; \\ 3. College of Mechanical and Electrical Engineering, Fujian Agriculture and Forestry University, Fuzhou 350002, China)
}

\begin{abstract}
Experiments were conducted to investigate the influences of type of litter, initial moisture content (IMC) of litter, and dry weight ratio of manure to litter (DWRML) on ammonia emissions from chicken manure and the effects of $\mathrm{pH}$ values of tea leaves and the mixtures of tea leaves and other litter on the ammonia emissions from chicken manure. For the experiments, four kinds of litter, Northeast pine sawdust (sawdust), rice husk, tea leaves, and wheat straw, were selected. The IMCs of the litter were $(20 \pm 2) \%$, $(30 \pm 2) \%$, and $(40 \pm 2) \%$; and the DWRML values were 1:4, 1:6 and 1:8, respectively. The different litters adjusted at different moisture contents were mixed with chicken manure in different DWRML and then placed in different static test chambers, which were real-time monitored the ammonia concentrations. Pure chicken manure without any litter was used as a control group. The four kinds of litter had obvious inhibitory effects on the ammonia emissions from chicken manure under various conditions. There were significant differences among four kinds of litter $(p<0.01)$. Under the same conditions, the best inhibitory effect was achieved by using tea leaves, followed by straw, rice husk, and sawdust. The IMC of litter had no significant effects on the ammonia inhibition $(p>0.05)$. The DWRML had no significant effects on ammonia emission inhibition for tea leaves $(p>0.05)$, but had a significant effects on the ammonia emission inhibition for the other three kinds of litter $(p<0.05)$. The $\mathrm{pH}$ value of tea leaves had no significant effects on the inhibition of ammonia emissions $(p>0.05)$. The mixed litter made of tea leaves and sawdust, rice husk, or straw were significantly better than the tea leaves and other single litter $(p<0.01)$. It indicated that adding appropriate amount of tea leaves in the litter can effectively inhibit ammonia emissions from chicken manure.
\end{abstract}

Keywords: litter, moisture content, dry weight ratio of manure to litter, chicken manure, inhibitory effect, ammonia emission DOI: $10.25165 /$ j.ijabe.20191204.5011

Citation: Tan H Q, Li M, Jie D F, Zhou Y F, Li X A. Effects of different litters on ammonia emissions from chicken manure. Int J Agric \& Biol Eng, 2019; 12(4): 27-33.

\section{Introduction}

For a long time, air quality in poultry houses has always been a focus, where ammonia is considered to be the main harmful gas to affect air quality. If the poultry stay in a high ammonia concentration environment for a long time, a stress reaction will be produced. When the ammonia concentration is high in the poultry house, the eyes and respiratory system of the animals will be damaged, and the longer the time the animals stay in the environment of high ammonia concentration, the more serious the damage will be. Damage to trachea and atrial tissues results in lowered resistance to various respiratory diseases and secondary infections such as airsacculitis, Escherichia coli infections and coccidiosis $^{[1-3]}$. About $80 \%$ of ammonia emissions come from livestock production in the United States and Europe, and the release of ammonia in livestock production is too large, causing great concern from governments ${ }^{[4-6]}$.

\section{Received date: 2019-03-02 Accepted date: 2019-06-18}

Biographies: Meng Li, Master, research interests: modern farming technology and equipment, Email: lmmeng0101@163.com; Dengfei Jie, PhD, research interests: environmental quality detection and control technology for livestock and poultry health culture, Email: dfjie@fafu.edu.cn; Yafang Zhou, Master, research interests: modern farming technology and equipment, Email: 15271920334@163.com; Xin’an Li, Master, research interests: modern farming technology and equipment, Email: lizimu2017@gmail.com.

*Corresponding author: Hequn Tan, PhD, Associate Professor, research interests: livestock and poultry health farming facilities and equipment. Huazhong Agricultural University College of Engineering, Wuhan 430070. Tel: +86-2787282120, Email: thq@mail.hzau.edu.cn.
In broiler raising, litter is usually used to adjust the environment in the poultry house, and the management of litter, such as the type and amount of litter, will affect the ammonia emissions in the poultry house ${ }^{[7]}$. In actual productions, the commonly used litter includes straw, rice husk ${ }^{[8,9]}$, sawdust ${ }^{[10]}$, etc. The litter was laid directly or after fermentation, which prevented broilers from coming into direct contact with the ground and promoted the absorption of manure moisture ${ }^{[11]}$ and reduction of ammonia volatilization and nitrogen loss in chicken manure. Some researches had found that the litter added with brown coal and microbial vaccine can improve the quality of the litter and the air in the house, thus promoting the growth efficiency of broilers ${ }^{[12]}$. The fermented litter made of Chinese herbal medicine residues can greatly reduce the average ammonia concentration in the house thus significantly improving the air quality in the house ${ }^{[13]}$. The ammonia emissions are affected by a combination of factors such as temperature, $\mathrm{pH}$, air exchange rate and moisture content of the litter in the house. Adjusting the $\mathrm{pH}$ value of the slurry to 5.5 can reduce the ammonia emissions by $75 \%-80 \%{ }^{[14]}$. When the $\mathrm{pH}$ value of slurry is greater than 7 , ammonia emissions will increase significantly ${ }^{[15]}$. The application of aeration to the storage of slurry can create an aerobic environment and reduce the degradation of odor through the biodegradation of volatile fatty acids. However, the reduction of volatile fatty acids will increase the $\mathrm{pH}$ value of the slurry and promote the conversion of $\mathrm{NH}_{4}{ }^{+}$to $\mathrm{NH}_{3}$, which increased the loss of ammonia volatilization ${ }^{[16]}$. Increased temperature of litter or the environment promotes ammonia emissions ${ }^{[17,18]}$. Increasing the air exchange rate can reduce the ammonia concentration in the poultry house, but it will increase the loss of ammonia volatilization ${ }^{[18,19]}$. If the moisture 
content of the litter is too high, it will cause hypoxia, which will reduce the activity of microbial enzymes and reduce the ammonia emissions $^{[19]}$. Moreover, the type of broiler chicken also affects the rate of ammonia volatilization ${ }^{[20]}$.

Related studies had found that tea extract polyphenols had better adsorption and removal effects on ammonia and hydrogen sulfide. The main reason may be that tea polyphenols reacted with ammonia to absorb it $^{[21]}$. Compared with rice husk and sawdust, refused tea leaves can better inhibit ammonia emissions ${ }^{[22]}$. It showed that refused tea leaves can also be used as a material in the breeding process to reduce ammonia emissions. According to relevant research, it was found that the tea leaves discolored after absorption of ammonia gas compared with the absorption of other gases. This may be due to the chemical reaction between catechins and ammonia in tea leaves, which reduced the ammonia concentration $^{[23]}$. Related studies had found that refused tea leaves can be used as a low-cost adsorbent to remove some drug contaminants from aqueous media, which has great potential in absorbing pollutants and improving the environment ${ }^{[24]}$.

In order to provide a reference for the selection and preparation of litter in actual production, this paper selected Northeast pine sawdust (sawdust), rice husk, straw, and tea leaves as research objects. They were mixed with chicken manure in different cases, with pure chicken manure as the control group, to explore the influence of the type of litter, the initial moisture content (IMC) of different litter and the dry weight ratio of manure to litter (DWRML) on the ammonia emissions from chicken manure and the effect of $\mathrm{pH}$ value of the tea leaves on the ammonia emissions from chicken manure and to study the effect of tea leaves mixed with other litter on the ammonia emissions from chicken manure.

\section{Materials and methods}

\subsection{Experimental material}

Wheat straw was taken from Hanchuan City, Hubei Province in China and chopped to 1-2 cm segments. Sawdust, specifically Northeast pine sawdust, was purchased from Lianyungang, Jiangsu Province in China. Rice husk was taken from Hanchuan City, Hubei Province in China. Low-grade green tea leaves produced in Enshi City were purchased from a tea market in Wuhan, Hubei Province. Fresh chicken manure was collected from a chicken farm in Wangchang Town, Tianmen City, Hubei Province in China.

The raw moisture content, total carbon (TC), total nitrogen $(\mathrm{TN})$ and carbon to nitrogen ratio $(\mathrm{C} / \mathrm{N})$ of various test materials are shown in Table 1.

Table 1 Composition of test materials

\begin{tabular}{cccccc}
\hline $\begin{array}{c}\text { Litter } \\
\text { Type }\end{array}$ & $\begin{array}{c}\mathrm{TC} \\
/ \mathrm{g} \cdot \mathrm{kg}^{-1}\end{array}$ & $\begin{array}{c}\mathrm{TN} \\
/ \mathrm{g} \cdot \mathrm{kg}^{-1}\end{array}$ & $\mathrm{C} / \mathrm{N}$ & $\begin{array}{c}\text { Moisture } \\
\text { content/\% }\end{array}$ & $\mathrm{pH}$ \\
\hline Chicken manure & 247.3 & 24.6 & 10.1 & 76.01 & 6.99 \\
Sawdust & 440.3 & 0.7 & 628.9 & 12.39 & 6.75 \\
Rice husk & 410.0 & 2.2 & 182.8 & 13.94 & 6.92 \\
Tea leaves & 539.2 & 28.4 & 19.0 & 9.38 & 5.81 \\
Wheat straw & 333.6 & 3.3 & 99.7 & 11.70 & 7.22 \\
\hline
\end{tabular}

\subsection{Experimental design}

\subsubsection{Single litter experiment}

The test factors were the litter type, the IMC of litter and the DWRML. The factor level table is shown in Table 2. Among them, the DWRML were set according to the amount of litter spread in the actual broiler rearing and the amount of manure broiler produced in the whole cycle. It was calculated that the amount of manure is about $42000 \mathrm{~g} / \mathrm{m}^{2}$, and the amount of litter is about $27136 \mathrm{~g} / \mathrm{m}^{2[22,25-27]}$. According to the moisture content of chicken manure and litter, the calculated DWRML is about 1:6, and the DWRML was set to 1:4, 1:6 and 1:8, respectively.

Table 2 Level of each factor

\begin{tabular}{cccc}
\hline Level & Litter type & The IMC of litter/\% & DWRML \\
\hline 1 & Sawdust & $20 \pm 2$ & $1: 4$ \\
2 & Rice Husk & $30 \pm 2$ & $1: 6$ \\
3 & Tea Leaves & $40 \pm 2$ & $1: 8$ \\
4 & Wheat straw & & \\
\hline
\end{tabular}

In the test, the amount of fresh chicken manure per test was $120 \mathrm{~g}$, corresponding to a dry weight of $28.8 \mathrm{~g}$. According to the DWRML set by the test, the amount of litter to be added for each test was calculated. The moisture required to adjust the litter to the IMC was added by spraying ${ }^{[19]}$. After adding the desired amount of water, the litter was mixed and placed for $2 \mathrm{~h}$, after which about $10 \mathrm{~g}$ of the litter was taken to determine the actual moisture content. The absolute error value of the IMC of the litter was less than $\pm 2 \%$.

A comprehensive test involving all levels of the factors listed in Table 2 was conducted. $120 \mathrm{~g}$ pure chicken manure without adding litter was used as a control group. The test was carried out in a laboratory controlled by air conditioning. During the test, the indoor temperature was controlled at $23^{\circ} \mathrm{C}-26^{\circ} \mathrm{C}$.

At each test, $120 \mathrm{~g}$ fresh chicken manure and the moisture-adjusted litter were evenly mixed and they were placed in the plastic pot and put in the test chamber. Timing started while the test chamber was closed. The ammonia concentration in the test chamber was monitored every 15 min during the test.

2.2.2 Tea leaves test for different $\mathrm{pH}$ values

The IMC of tea leaves was $(30 \pm 2) \%$. Before the test, the $\mathrm{pH}$ values of the tea leaves were adjusted to $6.77,7.72$, and 8.25 using $0.2 \mathrm{~mol} / \mathrm{L}, 0.5 \mathrm{~mol} / \mathrm{L}$, and $1 \mathrm{~mol} / \mathrm{L} \mathrm{NaOH}$ solution respectively, and untreated tea leaves ( $\mathrm{pH}$ 5.85) were used as control group. For each test, $120 \mathrm{~g}$ fresh chicken manure were weighed and mixed with tea leaves of different pH values to prepare a DWRML of 1:6. The mixture placed in a plastic pot was transferred into different test chambers. Timing started immediately when the test chamber was closed. During the test, the indoor temperature was controlled at $23^{\circ} \mathrm{C}-26^{\circ} \mathrm{C}$. The ammonia concentration in the test chamber was monitored every $15 \mathrm{~min}$.

\subsubsection{Mixed litter test}

The tea leaves and rice husk were mixed at a ratio of 1:9, 2:8 and 3:7 where rice husk without tea leaves was used as a control group. The tea leaves were mixed with sawdust, straw, and rice husk at a ratio of 3:7 and tea leaves without other litter were used as a control group. During the test, $120 \mathrm{~g}$ fresh chicken manure was weighed, and the litter was prepared according to the DWRML of $1: 6$, and the moisture content of litter was adjusted to (30 \pm 2$) \%$. The mixture placed in a plastic pot was transferred into different test chambers. Timing started immediately when the test chamber was closed. During the test, the indoor temperature was controlled at $18^{\circ} \mathrm{C}-22^{\circ} \mathrm{C}$. The ammonia concentration in the test chamber was monitored every $15 \mathrm{~min}$.

\subsection{Test equipment}

The test chamber was made of $6 \mathrm{~mm}$-thick transparent acrylic sheet (Figure 1). The size of the chamber and the basin were $0.5 \mathrm{~m} \times 0.4 \mathrm{~m} \times 0.5 \mathrm{~m}$ and $0.45 \mathrm{~m} \times 0.33 \mathrm{~m} \times 0.15 \mathrm{~m}$, respectively.

The devices utilized in this study included a 101-3AB electric blast drying oven (Tianjin Tianyi Technology Co., Ltd.), a PHS-3E 
acidity meter (Shanghai Yidian Scientific Instrument Co., Ltd.), a Q-300B high-speed multi-function pulverizer (Shanghai Bingdu Electric Co., Ltd.), a 9FQ-320 household universal pulverizer (Xing-yang City Agricultural Machinery Test Factory, Henan Province), a Multi N/C 2100 carbon-nitrogen element analyzer (Germany Jena Analytical Instrument Co., Ltd.), a Smartchem200 automatic chemical analyzer (Italian AMS Group), an AUY220 electronic analytical balance (Shimadzu Corporation), a COGO260 hygrothermograph (An Embedded Science and Trade Beijing Co., Ltd.), an INNOVA 1412i infrared photoacoustic spectrum gas monitor and 1409 multi-point sampler (Danish LumaSense).

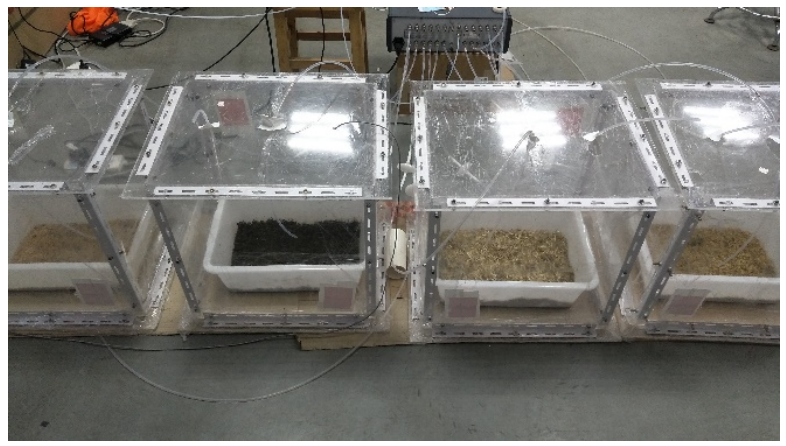

Figure 1 Test chamber

\subsection{Index determination}

The moisture content of the litter was determined according to GB/T 8576-2010 (Determination of Free Water Content in Compound Fertilizer-Vacuum Oven Method). The $\mathrm{pH}$ value of
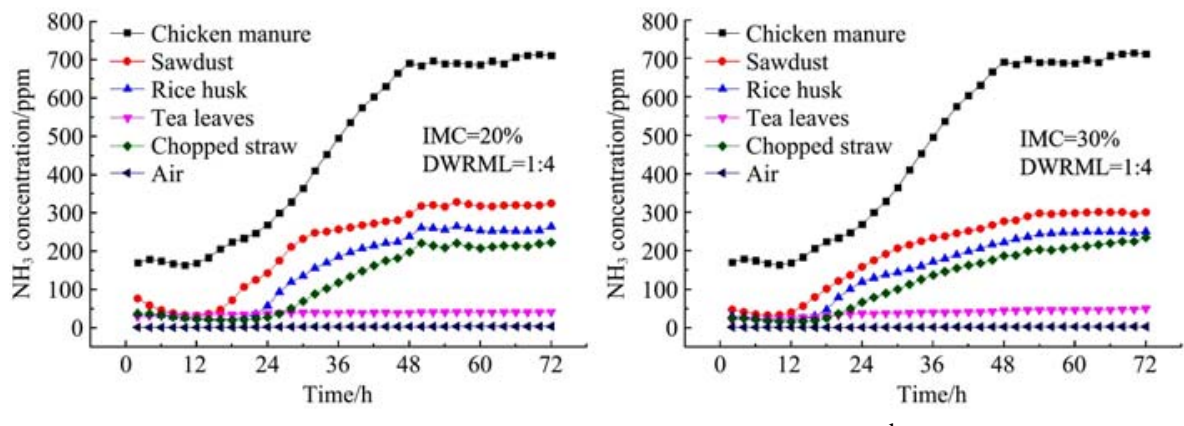

litter was determined according to NY525-2012 (Agricultural Industry Standard of the People's Republic of China - Organic Fertilizer).

TC measurement: Weigh about $0.1 \mathrm{~g}$ of air-dried pulverized sample, tiled in a ceramic boat and put it into a $1000^{\circ} \mathrm{C}$ tube furnace in a carbon-nitrogen analyzer. The sample TC is calculated according to the amount of $\mathrm{CO}_{2}$ compared to the standard curve ${ }^{[28]}$.

TN measurement: $0.1 \mathrm{~g}$ of air-dried samples was placed into the digestion tube and $5 \mathrm{~mL}$ concentrated sulfuric acid and $2 \mathrm{~mL}$ hydrogen peroxide was added for the first digestion and $2 \mathrm{~mL}$ hydrogen peroxide for a second digestion. Each digestion lasted for $1 \mathrm{~h}$. The digested solution was put into automatic chemical analyzer. The TN of samples was calculated according to solution color compared to standard color $^{[29,30]}$.

Ammonia concentration determination: The INNOVA1409 multi-point sampler was used to automatically collect air samples in each test chamber as well as the laboratory every $15 \mathrm{~min}$. The INNOVA1412i infrared photoacoustic spectrum gas monitor was used to measure and record the ammonia concentration of the gas sample after each sampling.

\section{Results and analysis}

\subsection{Inhibition of ammonia emissions by different litter}

The test results are shown in Figure 2. Each corresponding point in the Figure was extracted from the real-time data every $2 \mathrm{~h}$ after the start of experiment.

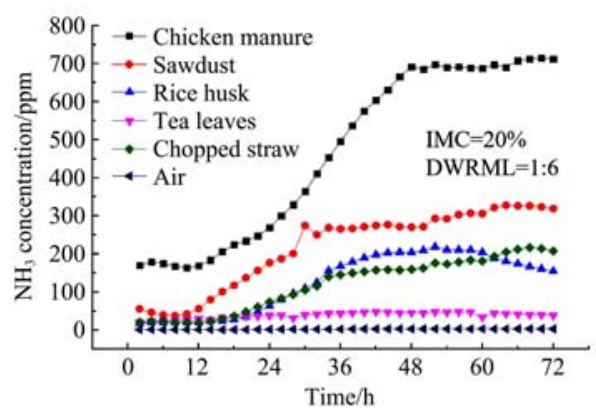

d

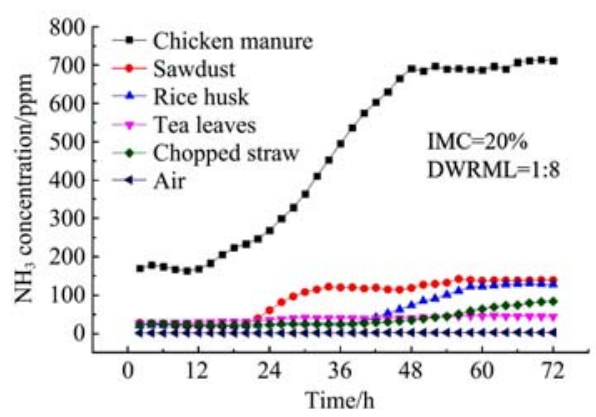

g

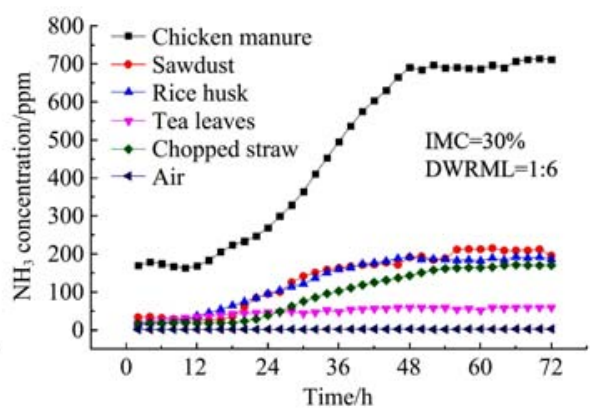

e

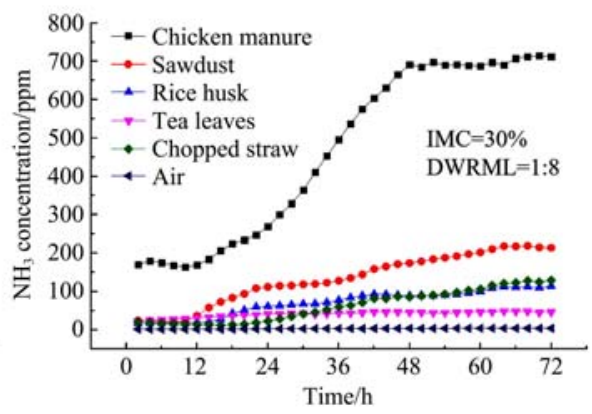

$\mathrm{h}$
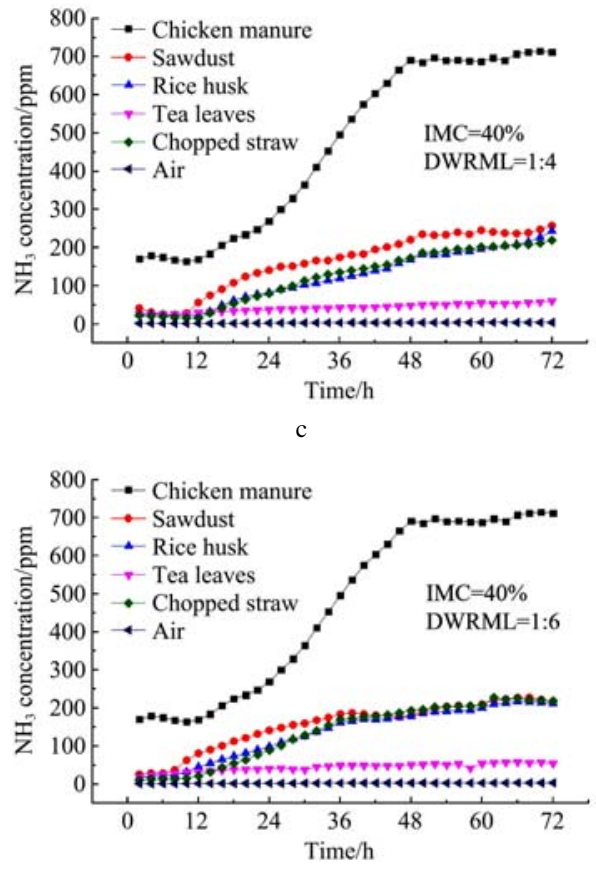

f

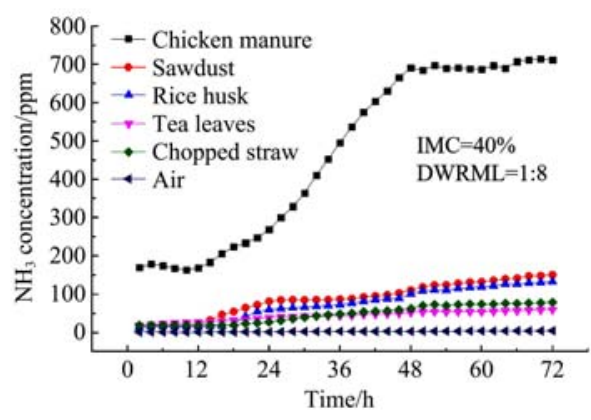

Figure 2 Comparison of ammonia concentration in different litter groups under the same IMC and DWRML 
From Figure 2, the ammonia concentration gradually increased with the prolongation of the test time for both the control groups (pure chicken manure group) and the litter test groups. The ammonia concentration of the control group was about $200 \mathrm{ppm}$ before $12 \mathrm{~h}$. It increased rapidly between 12-48 h and gradually stabilized between $48 \mathrm{~h}$ and $72 \mathrm{~h}$. The ammonia concentration of each litter group was not obvious before $12 \mathrm{~h}$. It gradually increased between 12-60 h, but the increasing rate of ammonia concentration was different. The difference of ammonia concentration among the groups gradually appeared. The ammonia concentration of each group tended to be stable between 60-72 h. In the first half test time of the control group and the litter test group, the ammonia concentration was in the rising stage because the oxygen was sufficient in the chamber when the test chamber was closed. In the condition, the microbial activity was intense and therefore a large amount of ammonia and carbon dioxide were generated. In the later stage, the microbial activity was slow due to insufficient oxygen in the chamber. The ammonia concentration tended to be stable in the test chamber.

At the specific time point, such as $12 \mathrm{~h}, 24 \mathrm{~h}, 48 \mathrm{~h}$ and $72 \mathrm{~h}$, the ammonia concentrations of the control group were $168.97 \mathrm{ppm}$, $269.48 \mathrm{ppm}, 691.19 \mathrm{ppm}$ and $712.32 \mathrm{ppm}$, respectively, which were significantly higher than that of the four litter groups $(p<0.01)$, indicating that the four kinds of litter have significant inhibitory effects on ammonia emissions from chicken manure.

The variance analysis of ammonia concentration at the specific time point, such as $12 \mathrm{~h}, 24 \mathrm{~h}, 48 \mathrm{~h}$ and $72 \mathrm{~h}$, showed that the ammonia concentration between the four litter groups was significantly different $(p<0.01)$. Further analysis showed that at $24 \mathrm{~h}$, the ammonia concentration in tea leaves group and straw group was significantly lower than that in rice husk group and sawdust group $(p<0.05)$. At $48 \mathrm{~h}$ and $72 \mathrm{~h}$, the ammonia concentration in the tea leaves group was significantly different from the other three groups $(p<0.05)$, but the difference of ammonia concentration between the straw group and the rice husk group was not significant $(p>0.05)$.

The IMC of sawdust group, rice husk group, tea leaves group and straw group had no significant difference in ammonia concentration at $12 \mathrm{~h}, 24 \mathrm{~h}, 48 \mathrm{~h}$ and $72 \mathrm{~h}(p>0.05)$, indicating the IMC of litter had no significant effect on the ammonia emissions from chicken manure. Liu et al. ${ }^{[19]}$ and Bessei et al. ${ }^{[31]}$ indicated that increasing the moisture content of the litter would promote microbial activity within a certain range, and this can increase the production of ammonia. At the same time, through some of the ammonia gas produced can be dissolved in the high moisture content of the litter in the form of $\mathrm{NH}_{4}^{+[32]}$, it will still be discharged as ammonia when the conditions are appropriate. Therefore, the high IMC of the litter is not conducive to the inhibition of ammonia emissions. In the actual poultry house breeding process, the moisture content of the litter should be controlled to ensure proper drying ${ }^{[33]}$, and the ideal moisture content should be maintained at $25 \%$ to $35 \%{ }^{[34]}$. The difference between three levels of DWRML of the tea leaves group was not significant ( $p>0.05$ ), indicating that three levels of DWRML of the tea leaves group had no different effect on the ammonia emissions from chicken manure in this experiment. The sawdust group, rice husk group and straw group had a significant difference between 1:8 group, 1:4 group and 1:6 group during 24-72 h $(p<0.05)$. There was no significant difference between 1:4 group and 1:6 group during 24-48 h $(p>0.05)$. At $72 \mathrm{~h}$, there was a significant difference in ammonia concentration between 1:4 group and 1:6 group $(p<0.05)$. This indicated that increasing the amount of litter can inhibit ammonia emissions effectively in the actual production. Since the inhibitory effect of tea leaves on ammonia emissions is strong, the amount of litter used can be reduced to some extent when tea leaves used as a litter material.

The physical and chemical properties of litter in livestock houses have a great impact on manure ammonia emissions, and different litter materials can affect ammonia emissions in different aspects ${ }^{[35]}$. $\mathrm{Ma}^{[36]}$ showed that covering the surface of pig manure with straw and sawdust can increase carbon dioxide emissions during the composting process, believing that this was due to the addition of straw and sawdust to increase the $\mathrm{C}$ content and promote microbial activity. Microorganisms consume C-containing substances to produce carbon dioxide, and also consume N-containing substances to produce ammonia. Therefore, the high C content of litter is beneficial to promote the activity of microorganisms and increase the emissions of ammonia and carbon dioxide. In this test, from the overall trend of ammonia concentration in the monitoring process, the ammonia concentration in the test chamber is ranked from high to low: pure chicken manure (control group) $>$ sawdust group $>$ rice husk group $>$ straw group $>$ Tea group. Based on the minimum ammonia concentration at $72 \mathrm{~h}$ measured by different litter materials under different IMC and different DWRML, the inhibitory effect of tea leaves, straw, rice husk, and sawdust on ammonia emissions from chicken manure can reach $94.58 \%$ (IMC $20 \% \pm 2 \%$, DWRML $1: 6$ ) and $88.85 \%$ (IMC $40 \% \pm 2 \%$, DWRML $1: 8$ ), $84.00 \%$ (IMC $30 \% \pm 2 \%$, DWRML $1: 8$ ) and $80.40 \%$ (IMC $20 \% \pm 2 \%$, DWRML 1:8), respectively. This order agrees with that of the litter $\mathrm{C} / \mathrm{N}$ in Table 1 . This indicated the result was similar to the research of $\mathrm{Ma}^{[36]}$, where $\mathrm{C} / \mathrm{N}$ affects the inhibitory effect of litter on ammonia emissions from chicken manure with lower $\mathrm{C} / \mathrm{N}$ of the litter for better inhibitory effect ${ }^{[37]}$.

\subsection{Effect of $\mathbf{p H}$ on the inhibition of ammonia emissions from tea leaves}

Wang et al. found that when adjusting $\mathrm{pH}$ value of the liquid manure to 5.5 , the ammonia emissions were significantly reduced by $40.2 \%$ in the liquid manure ${ }^{[17]}$. While Dai et al. concluded that when the $\mathrm{pH}$ values in pig manure were set to $6.0,5.8$, and 5.5 , the ammonia emissions finally were reduced by $50 \%, 62 \%$, and $77 \%$ respectively ${ }^{[38]}$. In this test, the $\mathrm{pH}$ values of four kinds of litter such as sawdust, rice husk, straw, and tea leaves were $6.75 \pm 0.15$, $6.92 \pm 0.10,7.22 \pm 0.13$ and $5.81 \pm 0.08$ before the test, respectively. The three kinds of litter, namely sawdust, rice husk and straw, are neutral and have little difference in $\mathrm{pH}$ value. It can be considered that the difference in the inhibitory effect on ammonia emissions from chicken manure is mainly due to the difference of $\mathrm{C} / \mathrm{N}$ and physical properties of the three materials ${ }^{[35]}$ while not correlated with $\mathrm{pH}$ values. Considering that the tea leaves are weakly acidic, this paper designed the litter experiment of tea leaves with different $\mathrm{pH}$ values in order to investigate whether the $\mathrm{pH}$ value affects the inhibitory effect of tea leaves on ammonia emissions. The test results are shown in Figure 3. Each corresponding point in the Figure was extracted from the real-time data every $2 \mathrm{~h}$ after the start of experiment.

It can be seen from Figure 3. After raising the $\mathrm{pH}$ value of the tea leaves to neutral or weak alkaline, the ammonia concentration is slightly increased compared with the acidic tea leaves group in the test chamber, but with no significant difference $(p>0.05)$. At $72 \mathrm{~h}$, the ammonia concentration in the test chamber were $35.22 \mathrm{ppm}$ at pH6.77, $42.04 \mathrm{ppm}$ at pH7.72, and $37.20 \mathrm{ppm}$ at 
$\mathrm{pH}$ 8.25, which were much lower than those for sawdust, rice husk and straw with the same moisture content and DWRML as well as similar $\mathrm{pH}$ values. This indicated that the effect of $\mathrm{pH}$ on the inhibition of ammonia emissions from tea leaves is not significant. Or in other words, the weak acidity of tea leaves was not the main reason for inhibiting ammonia emissions from chicken manure. This is consistent with the findings of Hile et al. ${ }^{[39]}$ and Lang ${ }^{[21]}$. Hile et al. ${ }^{[39]}$ found that changing the $\mathrm{pH}$ of the willow leaves did not significantly reduce ammonia emissions when using willow branches and sawdust as a litter for broiler rearing. The study by Lang $^{[21]}$ also showed that the absorption of ammonia was not significantly changed when the $\mathrm{pH}$ of the tea extract was adjusted from 5.5-6.0 to 8.2-8.6.

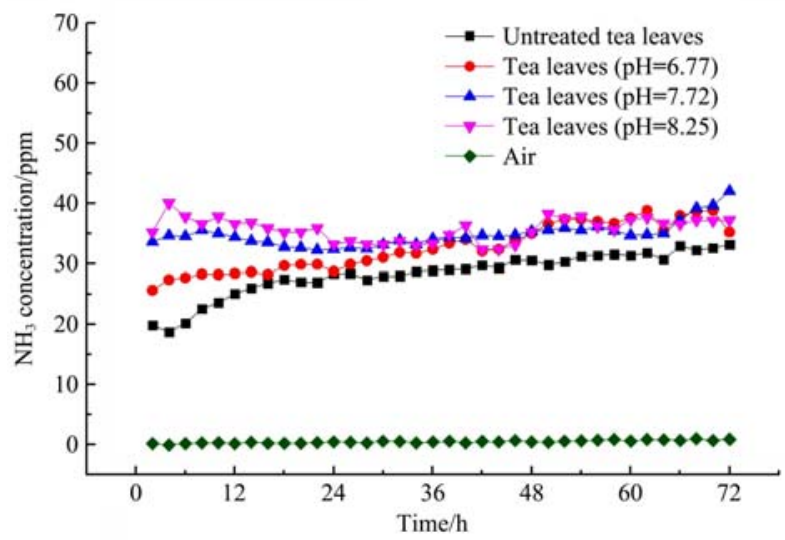

Figure 3 Trend of ammonia concentration in the mixture at different $\mathrm{pH}$ values of tea leaves

Among the four kinds of litter used in this paper, tea leaves have the best inhibitory effect on ammonia emissions from chicken manure, and this result is consistent with Atapattu's research ${ }^{[22]}$. Combined with the literature and the test results of this paper, it can be seen that the low $\mathrm{C} / \mathrm{N}$ and weak acidity of tea leaves can less reduce the ammonia emissions to a certain extent, but it can't be the main reason for strong inhibitory effect of tea leaves to ammonia emissions from chicken manure. The components in the litter of sawdust, rice husk and straw are mainly cellulose, lignin, etc. The increase of lignin content reduced the ability of these litter to act as a microbial growth substrate ${ }^{[22]}$. The main components of tea leaves are tea polyphenols, free amino acids and caffeine $^{[40]}$. Studies had found that tea extract has an obvious removal effect on ammonia and hydrogen sulfide, and the content of tea polyphenols had changed significantly during deodorization. It may be that the -OH group in tea polyphenols reacted with ammonia and hydrogen sulfide, and the tea extract had absorption and removal effects on ammonia. Takahashi et al. ${ }^{[23]}$ found that the chemical reaction of catechins of tea leaves with ammonia resulted in a decrease in ammonia concentration. The urea in the manure was decomposed by urease to produce ammonia ${ }^{[41]}$. However, studies had found that polyphenols can reduce the activity of urease ${ }^{[22]}$, thereby reducing the decomposition of urea. Therefore, the special components of tea leaves, which are different from sawdust, rice husk, straw and other common litter, and its complex biological activity should be the main reasons for tea leaves to inhibit ammonia emissions from chicken manure.

3.3 Effect of tea leaves on inhibition of ammonia emissions by rice husk, sawdust and straw

We prepared different proportions of mixed litter composed of tea leaves and rice husk to further explore the inhibitory effect of tea leaves on ammonia emissions from chicken manure and to provide a reference for the selection of litter in broilers rearing production. The test results are shown in Figure 4. Each corresponding point in the Figure was extracted from the real-time data every $2 \mathrm{~h}$ after the start of experiment.

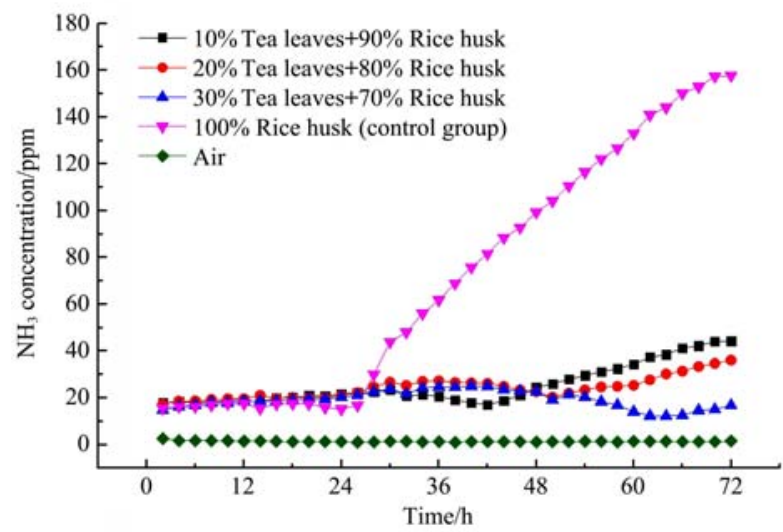

Figure 4 Trend of ammonia concentrations in the mixture of tea leaves and rice husk in different proportions

As shown in Figure 4, the difference of ammonia concentration was very small before $24 \mathrm{~h}$ in the test chamber among all types of litter. There was still no significant difference among the three mixed groups ( $p>0.01)$ in ammonia concentrations which, however, were significantly lower than that produced by the pure rice husk group between $24 \mathrm{~h}$ to $48 \mathrm{~h}(p<0.01)$. After $48 \mathrm{~h}$, the differences of ammonia concentration among the three mixed groups gradually appeared. With the extension of time, the inhibitory effect on ammonia emissions from chicken manure was better when the proportion of tea leaves were higher. At $72 \mathrm{~h}$, the ammonia concentration in the test chamber was $157.73 \mathrm{ppm}$ in the pure rice husk group, $44.28 \mathrm{ppm}$ in the $10 \%$ tea mixed group, $36.16 \mathrm{ppm}$ in the $20 \%$ tea mixed group, and $16.84 \mathrm{ppm}$ in the $30 \%$ tea mixed group, respectively. This indicated that adding a certain proportion of tea leaves to rice husk can significantly improve the inhibitory effect of rice husk on ammonia emissions from chicken manure in this test with higher proportion of added tea leaves for better inhibitory effect.

Mixed litter of tea leaves with sawdust, rice husk and straw according to the ratio of 3:7 was investigated. The results are shown in Figure 5. Each corresponding point in the Figure was extracted from the real-time data every $2 \mathrm{~h}$ after the start of experiment.

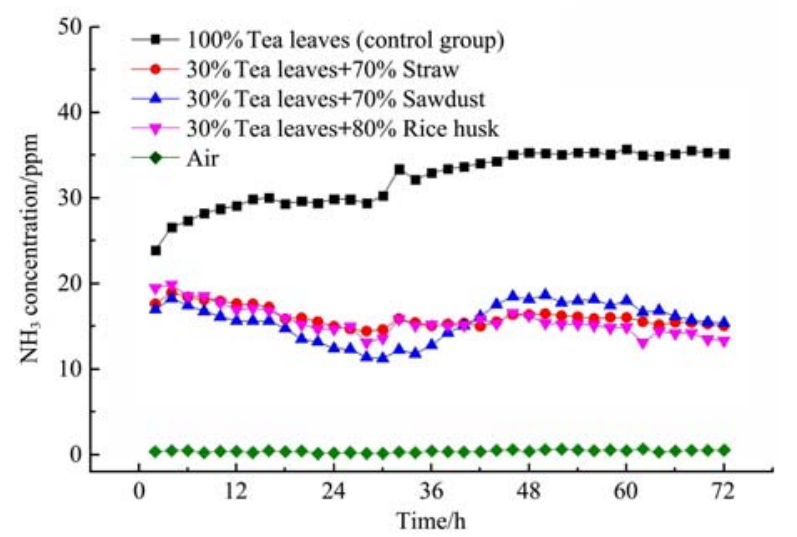

Figure 5 Trend of ammonia concentrations in the mixture of tea leaves with straw, sawdust and rice husk respectively

It can be seen from Figure 5 that the ammonia concentrations tended to be stable at a low level after a small increase in the three mixed test chambers, indicating that the addition of tea leaves can 
improve the ammonia emissions inhibitory effect of the three kinds of litter. It is worth noting that the ammonia concentration was significantly lower than that of the pure tea leaves group $(p<0.01)$ in the three mixed test chambers. The ammonia concentration was $35.21 \mathrm{ppm}$ for the pure tea leaves group, $15.09 \mathrm{ppm}$ for the straw mixture group, $15.44 \mathrm{ppm}$ for the sawdust mixture group, and $13.36 \mathrm{ppm}$ for the rice husk mixture group in the test chamber at 72 h. This illustrated that mixture litter could outperform pure tea leaves in inhibiting ammonia.

\section{Conclusions}

1) Tea leaves, sawdust, rice husk, and straw were shown to effectively inhibit ammonia emissions from chicken manure. Compared with pure chicken manure without litter, the inhibitory effect of tea leaves, straw, rice husk, and sawdust on ammonia emissions at 72 h can reach $94.58 \%$ (IMC 20\% $\pm 2 \%$, DWRML 1:6) and $88.85 \%$ (IMC $40 \% \pm 2 \%$, DWRML 1:8), $84.00 \%$ (IMC $30 \% \pm 2 \%$, DWRML $1: 8$ ) and $80.40 \%$ (IMC $20 \% \pm 2 \%$, DWRML $1: 8$ ) within the experimental conditions. There was a significant difference in the inhibition capacity of the four kinds of litter where tea leaves performed best.

2) The IMC of the litter had no significant effects on the ammonia emissions from chicken manure. Within the test range, the effect of DWRML on the inhibition of tea leaves was not significant. However, for sawdust, rice husk and straw, the low DWRML was more conducive to inhibit ammonia emissions from chicken manure.

3) The inhibitory effect of the litter on the ammonia emissions from chicken manure was related to the $\mathrm{C} / \mathrm{N}$ of the litter. The lower the $\mathrm{C} / \mathrm{N}$ of the litter was, the lower the $\mathrm{C} / \mathrm{N}$ was in the mixture with chicken manure, and the better was the inhibitory effect on ammonia emissions from chicken manure. The low $\mathrm{pH}$ value of tea leaves was not the main reason for its optimal inhibition. The inhibitory effect of tea leaves on ammonia emissions from chicken manure is mainly due to its special composition. However, this needs to be further tested and verified.

4) The mixed litter test results showed that adding appropriate amount of tea leaves to sawdust, rice husk, and straw can greatly improve the inhibitory effect of litter on ammonia emissions from chicken manure. When the proportion of tea leaves was 30\%, the inhibitory effect of the mixed litter on ammonia emissions was not only better than that of single sawdust, rice husk and straw, but also superior to pure tea leaves, which may be due to combined effects of tea leaves and other litter on the ammonia emissions from chicken manure. Nevertheless, its mechanism of action remains to be further studied.

\section{Acknowledgements}

We acknowledge that the present study was financially supported by the National Key Research and Development Program of China (2018YFD0500700) and Hubei Provincial Natural Science Foundation Youth Project (2017CFB160).

\section{[References]}

[1] Miles D M, Branton S L, Lott B D. Atmospheric ammonia is detrimental to the performance of modern commercial broilers. Poultry Science, 2004; 83(10): 1650-1654.

[2] Beker A, Vanhooser S L, Swartzlander J H, Teeter R G. Atmospheric ammonia concentration effects on broiler growth and performance. The Journal of Applied Poultry Research, 2004; 13(1): 5-9.
[3] Lott B. Ocular responses of ammonia in broiler chickens. AVIANDISEASES, 2006; 50: 45-49.

[4] Hutchings N J, Sommer S G, Andersen J M, Asman W A H. A detailed ammonia emission inventory for Denmark. Atmospheric Environment, 2001; 35(11): 1959-1968.

[5] Webb J, Menzi H, Pain B F, Misselbrook T H, Dämmgen U, Hengriks H, et al. Managing ammonia emissions from livestock production in Europe. Environmental Pollution, 2005; 135(3): 309-406.

[6] Erisman J W, Bleeker A, Hensen A, Vermeulen A. Agricultural air quality in Europe and the future perspectives. Atmospheric Environment, 2008, 42(14): 3209-3217.

[7] Torok V A, Hughes R J, Ophel-Keller K, Ali M, MacAlpine R. Influence of different litter materials on cecal microbiota colonization in broiler chickens. Poultry Science, 2009; 88(12): 2474-2481.

[8] Chamblee T N, Yeatman J B. Evaluation of rice hull ash as broiler litter The Journal of Applied Poultry Research, 2003; 12(4): 424-427.

[9] Brake J D, Boyle C R, Chamblee T N, Schultz C D, Peebles E D. Evaluation of the chemical and physical properties of hardwood bark used as a broiler litter material. Poultry Science, 1992; 71(3): 467-472.

[10] Nicholson F A, Chambers B J, Walker A W. Ammonia emissions from broiler litter and laying hen manure management systems. Biosystems Engineering, 2004; 89(2): 175-185.

[11] Garcia R G, Almeida P I, Caldara F R, Nääs I A, Pereira F D, Freitas L W, et al. Effect of the litter material on drinking water quality in broiler production. Revista Brasileira De Ciência Avícola, 2010; 12(3): 165-169.

[12] $\mathrm{S}^{3}$ obodzian-Ksenicz O, Houszka H, Michalski A. Effect of addition of brown coal and microbe vaccine to litter on bedding quality and production results in turkey farming. Animal Science Papers \& Reports, 2008; 26(4): 317-329.

[13] Liu X L, Zhang Y, Yan P P, Jing Q C, Wei X F, Liu R T, et al. Effects of different padding on air quality in broiler house and growth physiological index of broilers. Agricultural Science \& Technology, 2015; 16(12): 2764-2769.

[14] Kai P, Pedersen P, Jensen J E, Hansen M N, Sommer S G. A whole-farm assessment of the efficacy of slurry acidification in reducing ammonia emissions. European Journal of Agronomy, 2008; 28(2): 148-154.

[15] Dewes T. Effect of $\mathrm{pH}$, temperature, amount of litter and storage density on ammonia emissions from stable manure. The Journal of Agricultural Science, 1996; 127(4): 9.

[16] Zhang Z, Zhu J. Effectiveness of short-term aeration in treating swine finishing manure to reduce odour generation potential. Agriculture Ecosystems \& Environment, 2005; 105(1): 115-125.

[17] Wang K, Huang D, Ying H, Luo H. Effects of acidification during storage on emissions of methane, ammonia, and hydrogen sulfide from digested pig slurry. Biosystems Engineering, 2014; 122: 23-30.

[18] Nicholson F A, Chambers B J, Walker A W. Ammonia emissions from broiler litter and laying hen manure management systems. Biosystems Engineering, 2004; 89(2): 175-185.

[19] Liu Z F, Wang L J, Beasley D, Oviedo E. Effect of moisture content on ammonia emissions from broiler litter: A laboratory study. Journal of Atmospheric Chemistry, 2007; 58(1): 41-53.

[20] Coufal C D, Chavez C, Niemeyer P R, Carey J B. Nitrogen emissions from broilers measured by mass balance over eighteen consecutive flocks. Poultry Science, 2006; 85(3): 384-391.

[21] Lang X H. The experimental study on applying tea extract to deodorization in sewage treatment plant. Kunming: Kunming University of Science \& Technology, 2007. (in Chinese)

[22] Atapattu N S B M, Senaratna D, Belpagodagamage U D. Comparison of ammonia emission rates from three types of broiler litters. Poultry Science, 2008; 87(12): 2436.

[23] Takahashi T, Aso Y, Kasai W, Kondo T. Synergetic deodorant effect and antibacterial activity of composite paper containing waste tea leaves. Journal of Wood Science, 2011; 57(4): 308-316.

[24] Patil C S, Gunjal D B, Naik V M, Harale N S, Jagadale S D, Kadam A N, et al. Waste tea residue as a low-cost adsorbent for removal of hydralazine hydrochloride pharmaceutical pollutant from aqueous media: An environmental remediation. Journal of Cleaner Production, 2019; 206: 407-418.

[25] Institute of Agricultural Environment and Sustainable Development, Chinese Academy of Agricultural Sciences, Nanjing Institute of Environmental Sciences, Ministry of Environmental Protection. The first national survey of pollution sources - Handbook of source and discharge factors for livestock and poultry farming. 2009. (in Chinese) 
[26] Monira K N, Islam M A, Alam M J, Wahid M A. Effect of litter materials on broiler performance and evaluation of manureal value of used litter in late autumn. Litter Materials on Broiler Performance, 2003; 16(4): 555-557.

[27] Dan S, Jiao H E, Qiang W, Chang L L, Shi S R, Bu Z, et al. Effects of litter thickness on production performance, immune organ indexes, serum biochemical parameters and welfare quality of yellow-feathered broilers. Chinese Journal of Animal Nutrition, 2014; 26(8): 2357-2364.

[28] Elwinger K, Svensson L. Effect of dietary protein content, litter and drinker type on ammonia emission from broiler houses. Journal of Agricultural Engineering Research, 1996; 64(3): 197-208.

[29] Dai N, Zeng T, Mitch W A. Predicting $N$-Nitrosamines: $N$ -nitrosodiethanolamine as a significant component of total $N$-nitrosamines in recycled wastewater. Environ. Sci. Technol. Lett, 2015; 2(3): 54-58.

[30] Chen J L, Xie W X, Cui Y Q, Zhang Y. Research on the determination of total nitrogen and total phosphorus in soil using SmartChem140 automatic chemical analyzer. Journal of Analytical Science, 2016; 32(1) 84-88. (in Chinese)

[31] Bessei W. Welfare of broilers: a review. World's Poultry Science Journal, 2006; 62(3): 455-466.

[32] Liang W, Classen J J, Shah S B, Sharma-Shivappa R. Ammonia fate and transport mechanisms in broiler litter. Water Air \& Soil Pollution, 2014; 225(1): 1812

[33] Eriksson de Rezende C L, Mallinson E T, Tablante N L, Morales R, Park A, Carr L E, et al. Effect of dry litter and airflow in reducing salmonella and escherichia coli populations in the broiler production environment. Journal of Applied Poultry Research, 2001; 10(3): 245-251.
[34] Carey J B, Lacey R E, Mukhtar S. A review of literature concerning odors, ammonia, and dust from broiler production facilities: 2. flock and house management factors. Journal of Applied Poultry Research, 2004; 13(3): 509-513.

[35] Misselbrook T H, Powell J M. Influence of bedding material on ammonia emissions from cattle excreta. Journal of Dairy Science, 2005; 88(12): 4304-4315.

[36] Ma R J, Dong H M. Research status about main factors affecting gas emissions in liquid manure storage. Journal of Agricultural Science and Technology, 2010; 12(3): 56-61. (in Chinese)

[37] Coufal C D, Chavez C, Niemeyer P R, Carey J B. Effects of top-dressing recycled broiler litter on litter production, litter characteristics, and nitrogen mass balance. Poultry Science, 2006; 85(3): 392-397.

[38] Dai X R, Blanes-Vidal V. Emissions of ammonia, carbon dioxide, and hydrogen sulfide from swine wastewater during and after acidification treatment: Effect of pH, mixing and aeration. Journal of Environmental Management, 2013; 115(3): 147-154.

[39] Hele M L, Wheeler E F, Patterson P H, Hulet R M. Ammonia emissions from chopped willow versus pine shavings as bedding for broiler chickens. IX International Livestock Environment Symposium, ASABE, 2012.

[40] Wang X P, Zhou Z, Mo K J, Zhang J N. Comprehensive extraction technologies of active constituents of tea. Transactions of the Chinese Society of Agricultural Engineering, 2002; 18(6): 131-136. (in Chinese)

[41] Zhu L Y, Lu Q P, Zhang H F, Meng L H, Pang M. Ammonia production, hazards and mitigation measures in a pig house. Chinese Journal of Animal Nutrition, 2015; 27(8): 2328-2334. (in Chinese) 